\title{
The Construction of Placeness in Traditional Handicraft Heritage Sites: A Case Study of Suzhou Embroidery
}

\author{
Xiyue Zhang ${ }^{1}$, Yajuan $\mathrm{Li}^{2, *}$, Jing $\operatorname{Lin}^{3}{ }^{\mathbb{D}}$ and Yanjun $\mathrm{Ye}^{4}$ \\ 1 School of Humanities and Social Sciences, Beijing Institute of Petrochemical Technology, \\ Beijing 102617, China; zhangxiyue@bipt.edu.cn \\ 2 School of Urban and Environmental Science, Central China Normal University, Wuhan 430079, China \\ 3 Institute of Geographic Sciences and Natural Resources Research, Chinese Academy of Sciences, \\ Beijing 100101, China; linjingamy@163.com \\ 4 School of Earth Science and Engineering, Hebei University of Engineering, Handan 056038, China; \\ yecici3135@163.com \\ * Correspondence: yajuan.li@mail.ccnu.edu.cn; Tel.: +86-027-6786-2786
}

Citation: Zhang, X.; Li, Y.; Lin, J.; Ye, $Y$. The Construction of Placeness in Traditional Handicraft Heritage Sites: A Case Study of Suzhou Embroidery. Sustainability 2021, 13, 9176

https://doi.org/10.3390/su13169176

Academic Editor: Brian Garrod

Received: 26 June 2021

Accepted: 12 August 2021

Published: 16 August 2021

Publisher's Note: MDPI stays neutral with regard to jurisdictional claims in published maps and institutional affiliations.

Copyright: () 2021 by the authors. Licensee MDPI, Basel, Switzerland. This article is an open access article distributed under the terms and conditions of the Creative Commons Attribution (CC BY) license (https:// creativecommons.org/licenses/by/ $4.0 /)$

\begin{abstract}
Traditional handicrafts are rooted in the idea of the place, and their revival can trigger a construction of place in terms of physical buildings and cultural ambience. This study focuses on traditional Suzhou embroidery and analyses the effect of its revival on the construction of placeness and sustainable development within its specific social context. The results showed that (1) reviving traditional handicrafts triggers changes to local public spaces, the reshaping of local architecture, and the development of a cultural landscape; (2) The revival of the handicraft in terms of local activities is reflected in increased efficiency and creativity and in the stable inheritance of skills. The traditional farming lifestyle of Zhenhu has been transformed, leading to better quality of life and social networks; (3) The revival of Suzhou embroidery has updated the place through renovating its image. The local residents' awareness of the benefits of their handicrafts has also increased, and their increased dependence on place will strengthen their belongingness and attachment to it. These local changes exert positive impact on the realization of sustainable goals by boosting decent work and economic growth, ensuring environmental sustainability, building sustainable cities and communities, and enhancing community stability and cultural diversity. Thus, the revival of handicrafts can guide a place to refocus on local economic growth and cultural development towards sustainable development, bringing about an organic inheritance of its history and the reinforcement of placeness.
\end{abstract}

Keywords: placeness construction; traditional handicraft; intangible cultural heritage; sustainable development; Suzhou embroidery

\section{Introduction}

The humanist scholars Yi-Fu Tuan and Edward Relph introduced the concept of place to geography in the 1970s, and concepts such as place and placeness have since become central to the study of the man-land relationship [1,2]. Placeness refers to the uniqueness of place within a specific period of time and space and is essentially the meaning that people endow a space with [3]. Placeness is embodied in natural landscapes and local social behaviour and influences both local residents and social processes. A culture has its own unique logic, dynamics, and vitality [4], but placeness can be threatened by forces such as modernisation, globalisation, and rationalisation, which can render places static, dull, and lifeless [5]. Oakes, when addressing the phenomenon of modernisation, regarded the potential resulting loss of placeness as 'the paradox of modernity' [6]. In his book The Globalization of Nothing, Ritzier points out that globalisation is a complex interactive relationship between 'nothing' and 'something', and has brought about the expansion of nothing, thus depriving the 'something' of placeness of the basis for its survival [7]. 
Cultural heritage is rooted in places, and the ethnic historical memory and cultural connotations that it carries are important aspects of placeness. As emphasised in Ethical Principles for Safeguarding Intangible Cultural Heritage (2015) by United Nations Educational, Scientific and Cultural Organization (UNESCO), 'communities, groups and, where applicable, individuals should never be alienated from their own intangible cultural heritage' [8]. The intangible values, aesthetic qualities, and historical spirit of cultural heritage are closely associated with the space it emerges from in addition to its specific ethnic groups and communities. A deeper understanding of the value of intangible cultural heritage has recently developed in Chinese society, leading to the emergence of related activities such as the traditional handicraft industry. Among them, the handicraft ceramic industry in Jingdezhen of Jiangxi Province [9] and the jade carving industry in Jieyang of Guangdong Province are typical representatives [10]. This combines cultural heritage with commercial production. The sustainable development of intangible cultural heritage can help preserve its meaning through encouraging local protection, and its economic potential can be realised through local economic practices and industrial development. The revival of traditional handicrafts involves complex interactions between many factors, such as the revival of local culture, the development of local industries, and cultural communication. In this context, how does the revival of traditional handicrafts as a form of intangible cultural heritage influence the construction of placeness? How to realize local sustainable development through sustainable development of intangible cultural heritage? Addressing this question can inform research into both the sustainable development and placeness.

Suzhou embroidery, one of four renowned embroidery types in China [11], can be traced back more than 2500 years [12,13]. Most embroidery from the Suzhou region is currently produced in Zhenhu [14]. After a period of stagnation, Suzhou embroidery gradually developed and expanded [15], thus physically and culturally contributing to the construction of the place. The Suzhou embroidery developed in Zhenhu provides a special case for local research. Regarding how to achieve sustainable development in areas with strict control of industrial development, it has given a positive guidance and provided successful experience for reference.

Thus, in this study, the case of Suzhou embroidery was focused on to explore whether reviving traditional handicrafts can lead to the dissolution, adaptation, or strengthening of placeness, aiming to identify the mechanisms behind the process. Beyond that, the study explores the connection between the revival of traditional handicrafts and the sustainable development of the local area.

\section{Literature Review}

\subsection{Place and Placeness}

Place has been a core concept of cultural geography since the 1970s [16], and placeness has become a focus of geographical research. Humanistic and structuralist geography are two influential schools of thought in this field, and both focus on the concept of placeness. Cultural geography holds that the culture accumulated over a long period of time in a specific region and the cultural identity of its inhabitants endow placeness onto the region [17]. In humanistic geography, 'place' is conceived not as a material and rational space but is rather defined as 'the perceived core value'. The social significance and cultural meaning of place are important factors in the concept [18]. Structuralist geography holds that when a region establishes a functional connection with the outside world, its intrinsic uniqueness constitutes its placeness [19]. Representative works in this field include The Condition of Postmodernity by Harvey [20], The New Urban Frontier by Smith [21], and Reworking Modernity by Pred and Watts [22]. Although the two definitions of placeness appear different, they both suggest that placeness only occurs after a space has been endowed with meaning by people and that placeness distinguishes one place from others. Placeness is not only the emotional and historical heritage of tribes or ancestors' places [23], but it is also a process of social construction [24]. 
The two definitions of placeness in humanistic and structuralist geography also reveal their formation mechanisms. In humanistic geography, placeness is regarded as resulting from individuals' emotional attachment to a place. In his book Space and Place, Yi-Fu Tuan describes how space becomes a place through the process of being endowed with cultural meaning [3]. Humanist scholars regard the subjectivity of self and the experiences of daily life as the most important factors affecting the construction of place [2]. The unique meanings given to place by different groups and their identification with placeness in terms of concepts such as a sense of place, place identity, and place attachment have been explored. For example, Yi-Fu Tuan suggests that a place must be perceived by individuals through the feelings and emotions they experience, thus developing the concept of topophilia [1]. Relph emphasises that place represents the living world and consists of people's real-life experiences [2]. Thus, in humanistic terms, a place is not only a geographical space, but also is endowed with a special meaning and identity through human culture [25].

Structuralist geography holds that the functional needs of interconnecting regions determine the formation mechanism of placeness. In the spatial connections of social and economic networks, each place is assigned a role, which forms its characteristics. Scholars who hold this view, such as Gregory [26], Massey [27], and Harvey [20], focus on the construction of placeness through capital, power, institutional policy, and other structural forces. Macy's concept of a 'global sense of place' emphasises material socioeconomics and social relations in the processes of local production, and place is regarded as being formed via the integration of complex social relations through the internal and external flows of 'power geometry' in a specific local space [27]. Harvey also regards place as constructed through power, systems, and social relations rather than simply a location [28]. In the context of China's cultural system, the government and developers have been found to be central to urban renewal initiatives and the reconstruction and reproduction of placeness $[29,30]$. Capital and initiatives to preserve local arts are essential in determining whether a place retains its placeness [31].

Research into the reconstruction of placeness mainly focuses on tourism development, consumption space reconstruction, development zones, post-disaster reconstruction, and other local economic development processes. The complex process of dissolving or rewriting placeness has been illustrated through various examples. Tourism can have a powerful effect on the dissolution and reconstruction of placeness. Tourism activities may lead to the concept being abused and traditional culture may be damaged [32], but tourism revenue can also effectively protect local culture, promote cultural identification among community members, and cultural inheritance in tourist destinations [33]. Urban landscapes, however, such as historic neighbourhoods and skyscrapers, can lead to 'placelessness' and 'landscapelessness' [34,35]. Some scholars suggest that man-made consumption spaces such as shopping centres represent 'fake places' [36], a detachment from local culture, and a type of abstract globalised space [37], thus leading to a paucity of placeness [38]. Economic development zones can lead to the dissolution of placeness [39], while postdisaster reconstruction may provide opportunities for the reconstruction of placeness [40]. Thus, many structural factors influence the disappearance and reformulation of placeness, so strengthening and ensuring the continuation of placeness through intangible cultural heritage in the context of modernisation and globalisation is required, as this can encourage a renaissance of local culture.

Traditional handicrafts represent both human cultural achievements and important local cultural resources. This study examines the formation mechanism of placeness by focusing on how a place's cultural resources (traditional handicrafts) help to form its unique characteristics, thus extending the research on the formation mechanism of placeness in humanistic geography.

\subsection{Intangible Cultural Heritage, Tourism and Sustainability}

In 1987, the United Nations World Commission on Environment and Development (WCED) published a report, Our Common Future, with a definition of sustainable develop- 
ment as "a process of changes that are all in harmony and enhance both current and future potential to meet human needs and aspirations," which has since become a formal concept in the international agenda. The report also attached importance to the accumulations of traditional knowledge and experience, which could provide a great deal of traditional skills in sustainably managing very complex ecological systems [41]. In the decades that followed, the discussion has never ceased over the concept and essentials of sustainable development, as seen in the evolution from the originally defined sustainable use of natural resources to a pluralistic concept with people-oriented and socioeconomic features that involves economy, environment, society, and a series of legal principles [42]. The Sustainable Development Goals (SDGS-2015-2030), as a current guide, contains an explicit set of 17 global goals and 169 specific goals that universally extend to the economy, society, environment, culture and education, health, scientific, and technological development, indicating that sustainable development has vaulted to a new level [43].

Influenced by the broader policy goals pursued by the international community in the late 1990s, the Convention for the Safeguarding of the Intangible Cultural Heritage (the Convention) adopted by UNESCO in 2003 made an innovation of introducing Sustainable Development as the core concept. It not only emphasized the "intangible cultural heritage as a mainspring of cultural diversity and a guarantee of sustainable development" in the foreword, but it is also pointed out that international protection "will be given solely to such intangible cultural heritage as is compatible with the requirements of sustainable development" when defining the term "intangible cultural heritage" (ICH) in Article 2 [44]. These days, there are even scholars taking sustainable development as a legal principle of international cultural heritage law.

However, in the decade following the adoption of the Convention, the international community's discussion on the relationship between the protection of intangible cultural heritage and sustainable development waned. In the first 15 years of the 21st century, the "Millennium Development Goal" hardly mentioned the role of culture [45]. As a consequence, the concept of sustainable development was missing in 10 years of ICH practice and research. It was not until the United Nations adopted the Post-2015 Development Agenda that the cultural development issue became a topic again in the international debate. Since 2015, the United Nations General Assembly has included "Culture and Sustainable Development" as a sub-item under the agenda of "Globalization and Interdependence" (From the United Nations General Assembly resolution, A/RES/70/214), showing the will of the international community to make better use of culture in the process. From this point of view, the integration of ICH and sustainable development is actually the result of an evolving outlook on development by the UN system as a whole.

Cultural diversity is crucial to sustainable development because it correlates intangible cultural heritage to sustainable development. It took a while before this significance was recognized. In 1998, UNESCO held the Intergovernmental Meeting on Boosting Action Plan on Cultural Policies for Development, urging the world to acknowledge that culture is a key sector of human activities, an essential component of development process, an increasingly important driver behind economic growth, and the energy and cohesive force needed by all societies. According to Article VI of the Action Plan on Cultural Policies for Development passed at the meeting, all member countries agree that "cultural creativity is the source of human progresses; and cultural diversity as the wealth of human beings is an essential development element" [46]. The Universal Declaration on Cultural Diversity passed in 2001 is a milestone, further defining cultural diversity as "shared human heritage." Cultural diversity is the source of exchanges, innovation, and creation, and is "the key of sustainable human development". For the benefits of this generation and future generations, the importance of cultural diversity needs to be recognized [47]. Based on this consensus, the international community protects cultural diversity and intangible cultural heritage from the perspective of sustainable development.

It is therefore worth exploring how intangible cultural heritage affects sustainable development in other aspects. Due to the fuzziness of the concept itself, such significance 
has not been recognized in the implementation of the Convention. People tend to pay attention to the sustainability of only the heritage itself [48,49], ignoring the UN agenda of sustainable development. Most of the related studies are conducted as analyses of the relationship between ICH and some aspects of sustainable development in some cases. For example, Dernini studied the influence of Mediterranean dietetic customs on sustainable development [50], and Chung (2019) held that the ICH development was helpful to establish community identity, along with a discussion on the plausibility of the community promoting sustainable development for urban reconstruction [51].

At present, the impact of tourism development on heritage becomes a more concerned topic in discussing ICH sustainability. Such impact shall be weighed in multiple aspects. Positively, it could promote the revival and inheritance of traditional culture with national identity being strengthened. Negatively, it may lead to the variation or homogenization of traditional culture, such as the structural change or time-spatial compression of traditional songs and dances, and the desacralization of religious ceremonies, etc. There are in-depth research results obtained by scholars with a large number of cases for anthropological interpretation. According to the research of traditional handicrafts, tourism development has caused the genuine purpose of ICH handicrafts to change. Breaking away from the original context of folk custom, these handicrafts have become simply tourism commodities, with their traditional styles being affected, while such a phenomenon also encourages innovations of traditional handicrafts [52,53]. In some cases, this modern innovation may distort, simplify, misrepresent, damage, or change cultural symbols [54]. Owing to the expansion of the tourism market, the production of traditional masks has changed its style and way of manufacture. Tourism has hollowed the essence of cultural practices and caused the desacralization of ritual objects. At the same time, however, it is also the spring for the creation and re-creation of traditional practice with new meanings [55]. For the performance-related $\mathrm{ICH}$, the main findings are as follows. In the context of tourism, traditional dance is compressed in structure with the part of improvisation being shortened, and non-traditional musical instruments appear for accompaniment, thus making unreal ICH performances [56,57]. Hyung yu Park (2011) pointed that the ICH of Changdeokgung Palace played a supporting role in reconstructing and recontextualizing the national identity of South Korea in the tourism experience [58].

Although the impact of tourism on ICH is deeply explored, relevant studies are still confined to the sustainable development of ICH itself. Therefore, it requires further indepth research and case studies to explore the relationship between $\mathrm{ICH}$ protection and local sustainable development and how ICH development can help to realize the goals of local sustainable development.

\section{Study Area and Methods}

\subsection{Study Area}

Zhenhu is a peninsula surrounded by Taihu Lake on three sides and is located in the westernmost part of Suzhou City, Jiangsu Province (Figure 1) [59]. Zhenhu is a sub-district in terms of its administrative division, is equivalent to a town, and covers a total area of $20.1 \mathrm{~km}^{2}$ [59]. To protect Taihu Lake as a water source, Zhenhu is deemed an ecological protection zone and industrial development is strictly controlled. Any polluting enterprises, such as chemical plants and paper mills, have been shut down or relocated [60]. Thus, Zhenhu is one of the few remaining original ecological locations in the area and has been unaffected by industrialisation from the suburbs of Suzhou. It has maintained its natural environment and features well-preserved traditional villages. These villages, the Taihu Lake, and the art of embroidery represent a symbiosis between ecology and culture in Zhenhu [61].

Zhenhu has been an agricultural area since ancient times, with rice as the main crop. During the slack season, men engage in fishing and women do embroidery, which represents the main traditional sideline of Zhenhu farmers [62]. Zhenhu's Suzhou embroidery was included in the National List of Intangible Cultural Heritage of China in 2006 [63], 
and Zhenhu was also deemed a National Cultural Industry Demonstration Base by the Ministry of Culture [64]. Zhenhu is therefore the most renowned centre for embroidery in China. Its products are sold in cities throughout China and in other countries and regions of the world, such as Japan, South Korea, Southeast Asia, Europe, and the U.S. [65].
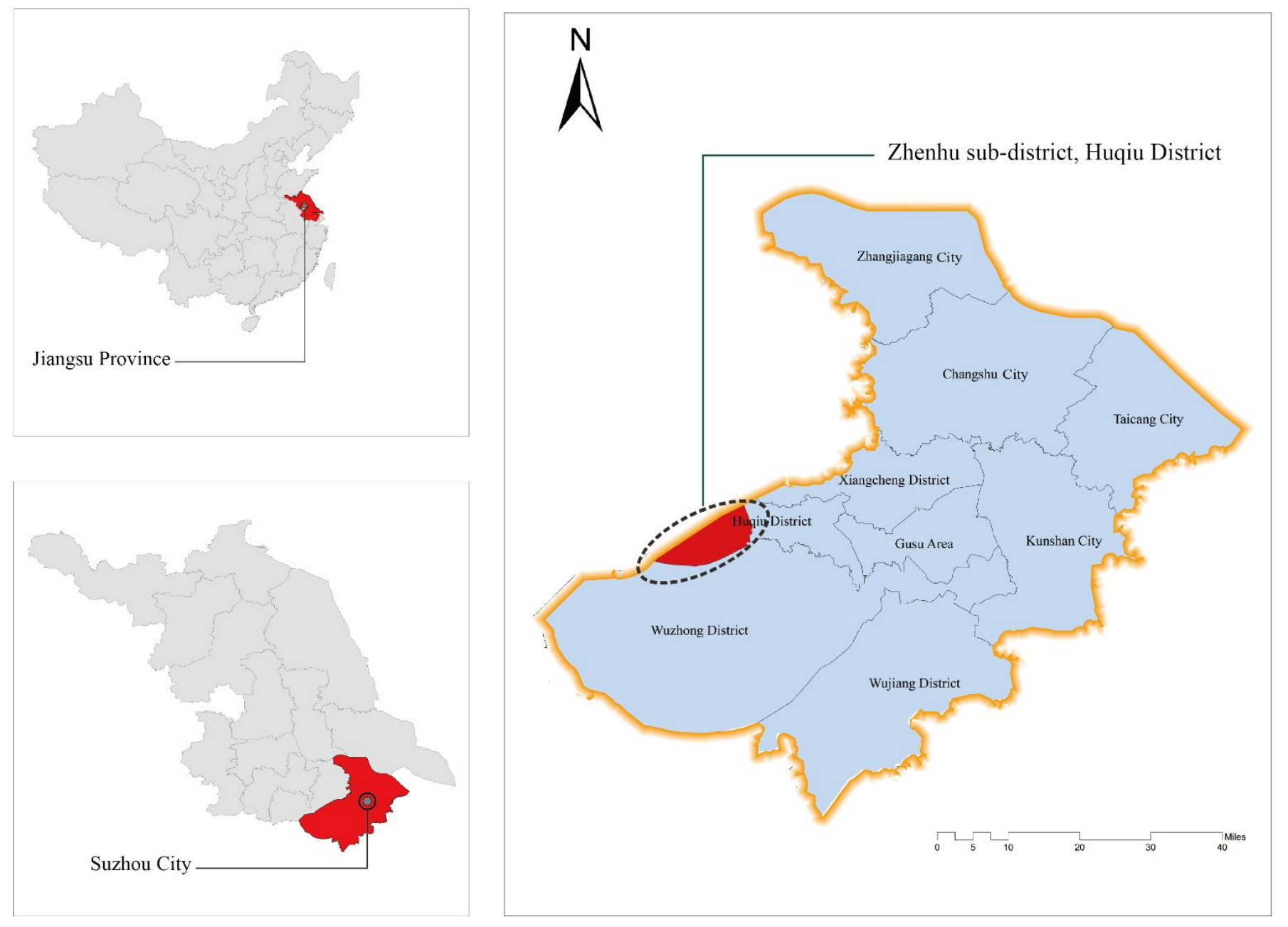

Figure 1. Geo-location of the case study: Zhenhu. Source: Authors.

\subsection{Research Methods and Data Sources}

The authors conducted a preliminary survey in Zhenhu in September 2016, mainly in the form of field observations, and collected extensive secondary material such as village records and website information relating to Zhenhu to gain a basic understanding of the location. A 28-day field survey was conducted in June 2019 using the non-participant observation method to collect first-hand information about local embroidery practitioners, ordinary residents' daily practices, and the local physical landscape. In-depth interviews were conducted to elicit the perceptions of various groups about the development of Zhenhu's Suzhou embroidery, the changes that have occurred, and their levels of identification with it. A supplementary survey was conducted in April 2020 with 52 interviews, 35 of which were in-depth. Audio recording was used as much as possible during the interviews to ensure the integrity of the information. Note-taking was used when interviewees declined to allow their conversations to be recorded. The interviewees included 3 senior craft artists (No. SCR1-SCR3), 10 embroideresses (women or girls who do the embroidery) (No. E1-E10), 5 embroidery studio owners (No. ESO1-ESO5), 5 local government officials (No. GO1-GO5), 3 tourists (No. T1-T3), and 6 local residents (No. R1-R6). 
The interview questions were aimed at understanding the urban construction and transformation process and the planning and development orientation of Zhenhu, at identifying changes in public spaces, landscapes, economic activities, cultural activities, residents' lives, and Zhenhu's image, and at examining the perceptions and attitudes of local people and tourists about the changed Zhenhu. Discourse analysis was used to understand various actors' expressions of Zhenhu's placeness and the social meanings implied by their discourse. It started with going through all interviews multiple times to sketch the process of construction of place as a whole, which was followed by an indepth immersion into each statement in its context to highlight significant narratives. The interview text, in the second stage, was decontextualized, sorted, and organized into fragments of meaning [66]. In the third step, the researchers went through all the meaningful corpus fragments several times to determine the framework of the analysis. Fourthly, researchers categorized meaningful segments of the corpus within the research framework and identified significant statements. In the fifth step, authors reflect upon the corpus of the significant statements to Generalize specific conclusions, which were subsequently reintegrated to forms the basic structure of the analysis in the sixth step. To ensure credibility and trustworthiness, data analysis and interpretation were triangulated among the authors [67]. The first author transcribed the records, categorized the transcripts into fragments of meaning, identified significant statements within each analysis fields. This process was repeated by the second author and triangulated with the first author [68]. The third author brought reflexivity to the analysis and interpretation. Conclusions were developed based on a consensus among the authors [69].

\section{Findings}

Suzhou embroidery in Zhenhu dates back more than 2500 years. The craft developed over a long time and was very common as early as the Warring States period (475-221 B.C.). In Zhenhu, 'In every boudoir there is an embroidery stand, and every woman and girl is skilful at needlework' [70]. Suzhou embroidery enjoyed its peak in the Ming Dynasty (1368-1644) and the Qing Dynasty (1636-1912), when embroidery products were very popular with the royal families. The folk embroidery of the time was rich and colourful, and was widely used for clothing, costumes, quilt covers, pillowcases, shoes, satchels, fan bags, etc., with patterns symbolising festivity, longevity, and good luck [71]. The numerous wars between the late Qing Dynasty and the Republic of China period (1912-1949) prevented any substantial further development of embroidery [72]. From the founding of the People's Republic of China to the beginning of the Cultural Revolution (1949-1967), production recovered and enthusiasm for culture and art gradually returned. Many high-quality embroideries resulted, and in the 1960s, Suzhou embroidery was produced throughout the suburbs of Suzhou [73]. During the decade-long Cultural Revolution (1968-1978), embroidery artisans suffered, many traditional pattern materials were destroyed, and the development of embroidery again came to a halt [74].

After the Cultural Revolution, Suzhou embroidery enjoyed a period of recovery and development, but as traditional handicrafts require great patience and perseverance, the skill declined rapidly under the impact of industrialisation, with fewer young people engaged in Suzhou embroidery. The villages and towns where traditional Suzhou embroidery was concentrated rapidly disappeared [15]. Dongzhu Sub-district and Tong'an Town around Zhenhu share the same embroidery tradition $[75,76]$, but in recent years, Dongzhu has shifted its production focus from handicrafts to high-tech products, and Tong'an Town has focused on the development of modern agriculture and eco-tourism because of its extensive agricultural resources $[77,78]$. Embroidery has disappeared from Dongzhu and Tong'an, and Zhenhu is now the only area of traditional Suzhou embroidery production remaining in Suzhou.

Zhenhu's embroidery industry and the Suzhou embroidery culture evolved from a state of complete stagnation to another golden age over the 40 plus years since the end of the Cultural Revolution. The development of embroidery skills, numerous innovations, 
and robust market demand have led to the revitalization of traditional handicrafts in Zhenhu. This study focuses on this historical process and analyses the construction of placeness in terms of physicality and culture, as driven by the revival of handicrafts in contemporary society.

\subsection{Construction of the Physical Space Form}

Physical changes in the place chosen for the case study mainly occurred in public spaces. Although the appearance and style of newly constructed residential areas in private spaces have changed, these are consistent with changes in public spaces, so the construction of public spaces is our main focus.

\subsubsection{Reproduction of Public Spaces}

The revival of traditional handicrafts and the reproduction of local public spaces are two mutual and embedded development processes. The focus of this study is on the development of Zhenhu's Suzhou embroidery from a state of complete stagnation to the re-establishment of embroidery culture after the rapid development following the end of the Cultural Revolution. The changes to the public spaces of the place are closely related to the revival (Figures 2 and 3). The process can be roughly divided into three stages.

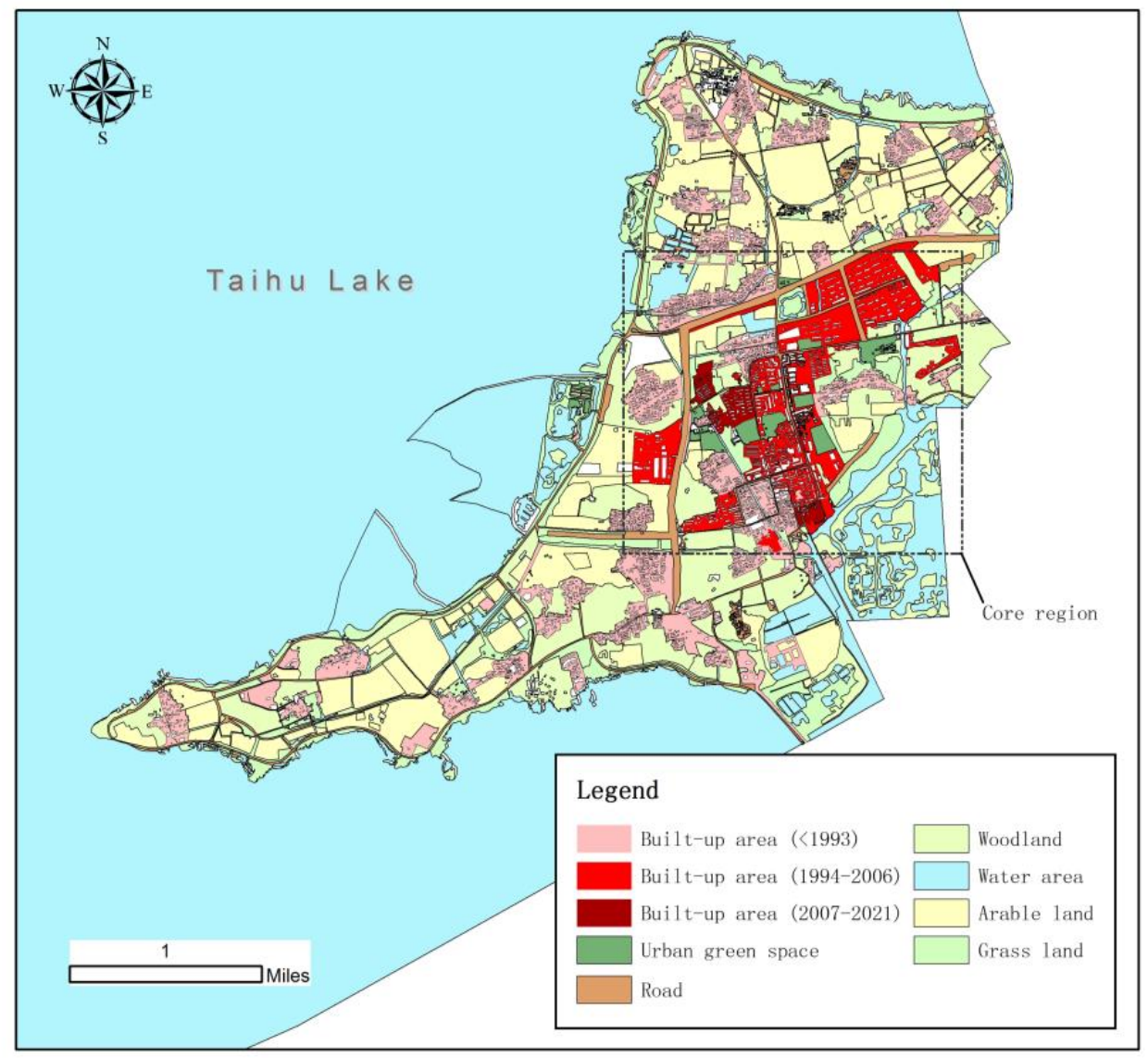

Figure 2. Changes of local public space in different development periods of the case study: Zhenhu. Source: Authors.

Slow development stage (1978-1993): The traditional home-based handicraft of Suzhou embroidery, which was dormant during the Cultural Revolution, began to recover, and the decentralised home-based, workshop-style craft production and operation were restored [15]. During this period, rural women continued their embroidery skills at home in their spare time. They worked for collective embroidery stations in villages and towns in exchange for a small fee that helped with their household expenses (Past scenes 
were pieced together from the memories of several local interviewees). The development of embroidery during this period had no significant impact on public spaces. As a traditional agricultural area, Zhenhu was a disorderly mixture of farmland and residential buildings [62], which were scattered and unplanned, so the overall landscape was not particularly conducive.

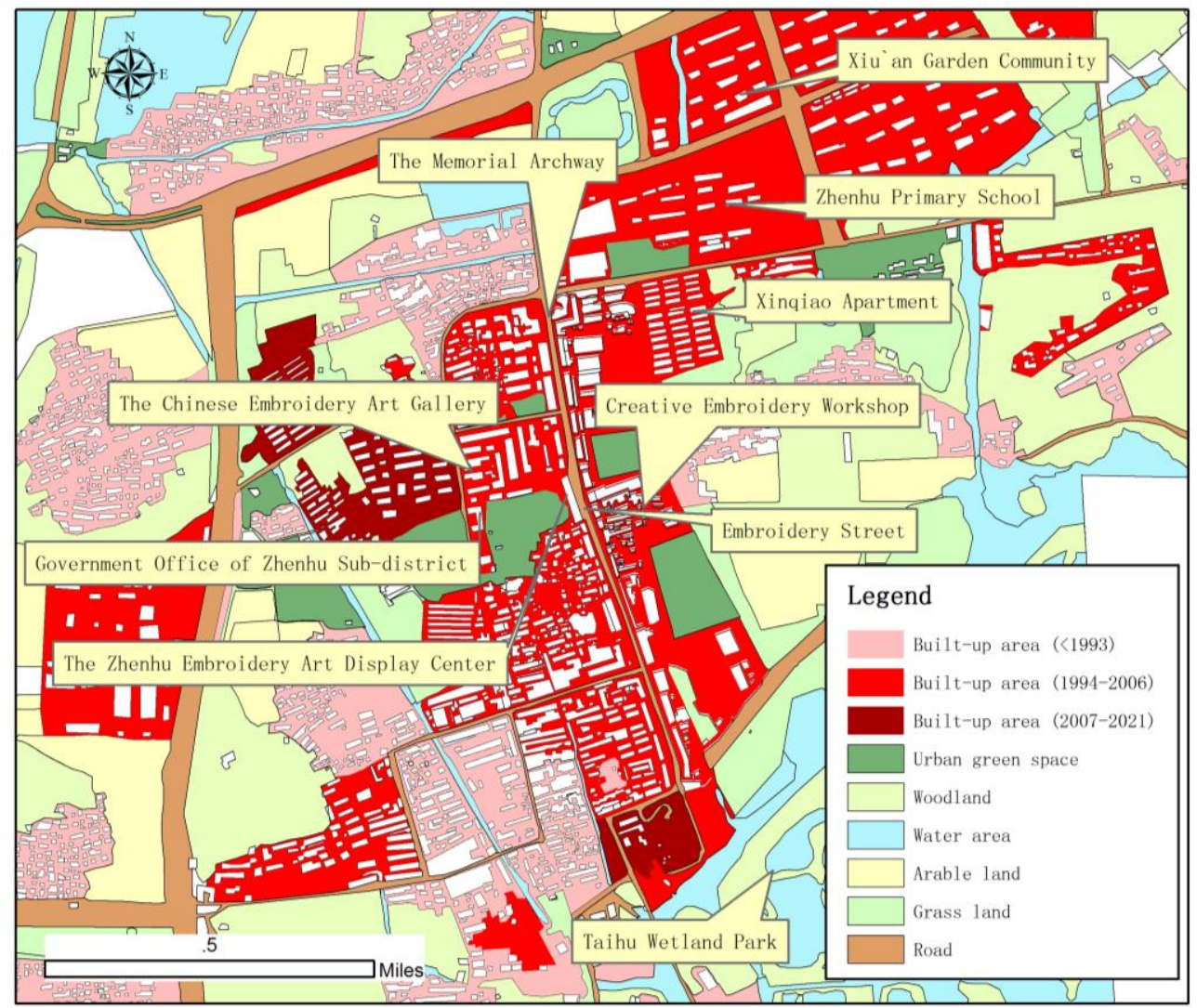

Figure 3. The changes of the core region of Zhenhu in different development periods. Source: Authors.

Rapid development stage (1994-2006): Private self-employed households gradually increased in number, private embroidery factories emerged to conduct small-scale specialised production and sales, and embroidery gradually changed from a household sideline to a private sector of the self-employed [72]. To meet the needs of this developing embroidery industry, the Zhenhu government built Embroidery Street, which provided specialised market buildings and centralised fixed business premises for Zhenhu's embroideresses [79]. This led to major changes in the form and function of the place's physical spaces. First, a central focus began to emerge in the place. Embroidery Street has become the centre and main street of Zhenhu, with the busiest daily pedestrian flow. The memorial archway at the entrance of Embroidery Street has become symbol of the place: 'There was no landmark in Zhenhu before. Now the memorial archway of Embroidery Street is a landmark' (R2); 'This is the core of Zhenhu and the most popular street' (R5). Second, in terms of physical form, the place has transformed from farmland and residential buildings to modern commercial streets and large-scale architectural edifices. In terms of functionality, it has changed from an agricultural production space to a functionally complex public space, which is not only a place where handicrafts are produced, sold, and inherited, but also a space where local residents live and interact: 'Embroidery Street is a street whose development we have been concentrating on since 1998, and now it has become the business and commercial centre of all of Zhenhu. It provides an important platform for the development of the embroidery industry, forms an industrial integration development belt, and integrates the important multifunctions of commerce, 
business, exhibition, and exchanges' (GO2). Third, the formerly fragmented and decentralised distribution pattern of the productive public spaces has transformed into a clustered pattern. Embroideresses practiced traditional embroidery at home, but Embroidery Street now brings together more than 300 embroidery studios [61], thus concentrating the production that was previously scattered across rural areas. The establishment of Embroidery Street has introduced industrial cluster-type development to embroidery.

Comprehensive revitalisation stage (2007-present): The embroidery talent base has continued to grow [80], and ordinary embroidery workers have developed into embroidery artists whose skills are constantly updated [81], and thus, Zhenhu's Suzhou embroidery culture has entered another golden age. The handicraft revival has shifted from industrial to cultural as the embroidery culture has received more public attention. Related cultural events such as exhibitions, forums, and competitions are now held in Zhenhu, and festivals and events have further promoted Zhenhu's Suzhou embroidery culture [81]. The structure and function of the place's public spaces have changed and are reflected in the following aspects. First, the construction of physical platforms or centres of embroidery culture has increased, and two major projects have been implemented: the Chinese Embroidery Art Gallery and the Zhenhu Embroidery Art Display Center [82]. The Art Gallery is a venue for events and has become the place's cultural activity centre, and the Art Center showcases and sells high-end embroidery products [61,79]. Second, the aesthetics of public spaces have improved significantly. The Chinese Embroidery Art Gallery, integrating resources such as Embroidery Street and a Creative Embroidery Workshop, became a national AAAA tourist attraction in 2013 (The term "National AAAA tourist attraction" is a scenic spot grading given according to $<$ Standard of rating for quality of tourist attractions > (No.: GB/T 17775-2003), which specifies five scenic spot grades, respectively, AAAAA, AAAA, AAA, AA, and A in the descending order) [83]. The core neighbourhoods have also undergone many rounds of improvement in terms of appearance and facilities, including comprehensive improvement programs for memorial archways, road greening, store images, waste pipe network settings, and street light landscapes [84]. Zhenhu no longer has the appearance of an agricultural town: 'In the past, there were only farmland around Embroidery Street, and the roads were dirt roads. Now the place as a whole looks very neat, much more beautiful than before. It has also become a scenic spot with green spaces and sculptures on the street. Public bus services are provided, so it's very convenient for us to get around' (R3).

In summary, the revival of traditional handicrafts has gone through the three-stage development process of the recovery of home-based handicrafts-industrial revival-cultural revival. Driven by the development of the embroidery industry, Zhenhu's local government initiated large-scale neighbourhood construction and space reconstruction. The form and function of the place and its physical appearance have generally changed for the better as a result. The revived public spaces integrate productive, living, and aesthetic functions. The place now has a centre and a landmark. The spatial distribution of the embroidery industry has changed from fragmented and decentralised to a clustered pattern. Zhenhu is no longer an agricultural town in appearance and has become a modern, urban, built-up area.

The change in production space boosts the production and trading efficiency of traditional handicraft, injects vigor to economic growth, and increases the incomes of the residents by creating more jobs. The change in the public space in Zhenhu solves issues such as inconvenient traffic, lacking sewage treatment facilities and infrastructures, and poor living conditions, improving the local operation mechanism. All these efforts make Zhenhu a convenient, comfortable, and safe living area with sound environments. These changes are essential to build a sustainable community.

\subsubsection{Reformulation of Local Landscapes}

To address the public's geographical imagination of Suzhou embroidery, low-rise residential buildings in Zhenhu neighbourhoods have been transformed into exquisite classical buildings in the Jiangnan style, which has changed the local architectural landscape. Embroidery Street has a grand welcome archway at its entrance and is lined with 
white-washed buildings with black tile roofs and flickering palace lanterns (Figure 4). The art gallery's appearance is reminiscent of a patterned classical and quaint Suzhou garden (Figure 5). However, this style is not the traditional architectural form of Zhenhu. The buildings in Zhenhu were traditionally low, rambling farmhouses with no such white walls and black tiles, as it was an agriculture-dominated and modest town [62]: 'In the past, there was no such memorial archway in Zhenhu. It was all farmland, and the houses were very ordinary, without distinctive features' (R2). Suzhou embroidery is the cultural symbol of Suzhou. The public perception of Suzhou embroidery involves the geographical imagining of Suzhou and Jiangnan $[85,86]$. Applying the Jiangnan architectural style to Zhenhu fits with the public geographical imagination of the origin of Suzhou embroidery, and thus creates a complete local cultural image. This architectural landscape later became a symbol of the place. This symbol has been constantly reinforced in the process of projecting the place's image to the outside world, and it has become an important medium for portraying the local image. Thus, Zhenhu's landscape has been transformed and its placeness has also changed accordingly.

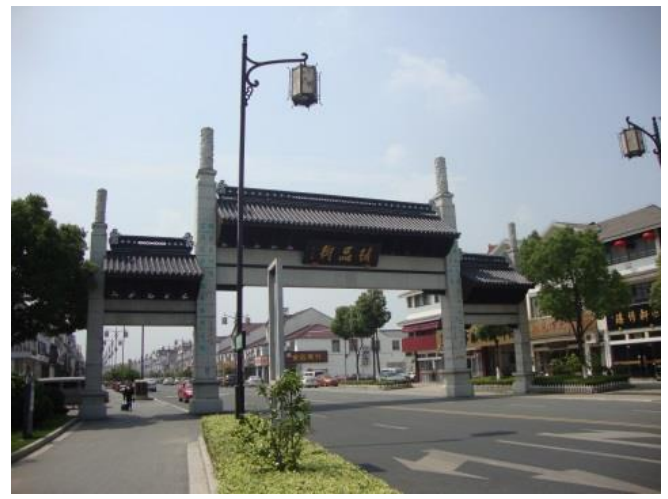

(a)

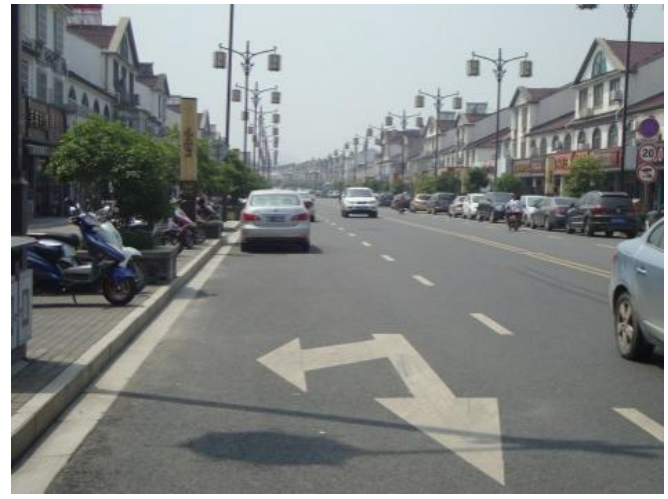

(b)

Figure 4. (a) The memorial archway at the at the entrance of Embroidery Street; (b) Street view of the Embroidery Street.

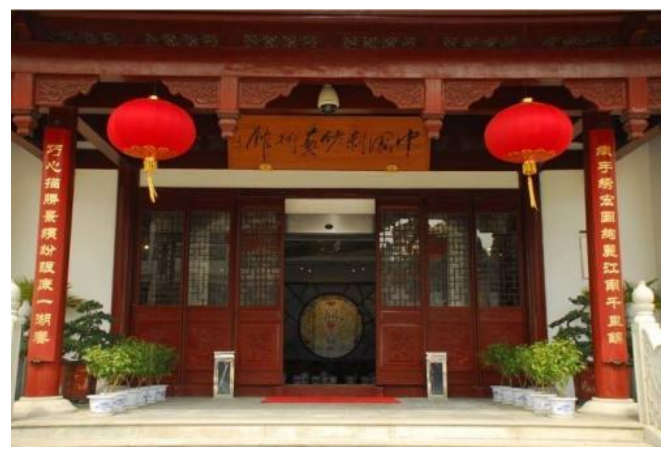

(a)

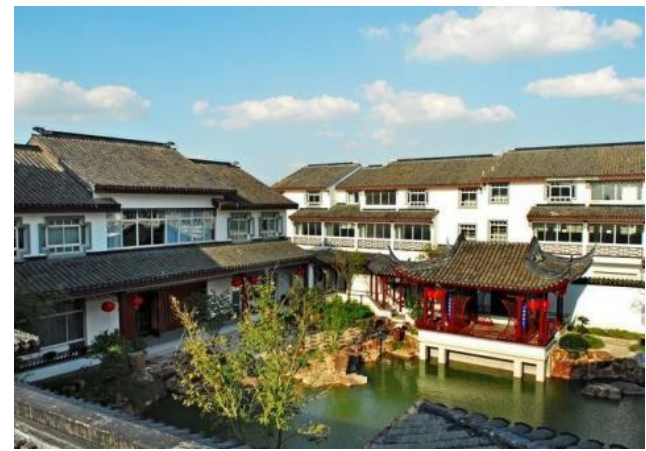

(b)

Figure 5. (a) The gate of the Chinese Embroidery Art Gallery; (b) The courtyard inside the gallery.

With its reformulated local architectural landscape, Zhenhu presents a comprehensive display of the Suzhou embroidery culture, thus forming a cultural landscape of Suzhou embroidery that includes elements such as production areas, workplaces, producers, and Jiangnan buildings. Embroideresses previously stood in long queues at embroidery stations to collect their work and deliver their products. Their embroidery was produced in private spaces (Various events throughout the history were summarized according to memories of several local interviewees) and therefore did not constitute a cultural landscape in public spaces. Various exhibits highlight Suzhou embroidery culture, and an extremely accessible cultural landscape has thus come into being in Zhenhu. Public sculptures 
depict embroidery scenes (Figure 6), embroideresses can be watched at work in their studios and private art galleries along the street, and the Chinese Embroidery Art Gallery presents a comprehensive view of Suzhou embroidery culture through images, objects, texts, and guided visits (Figure 7). Exhibitions feature exquisite embroidery products, the embroidery process, pattern designs and their meanings, important figures and events, and tool evolution (Presented as observed during the survey). The art gallery also offers a variety of experiences: 'The Chinese Embroidery Art Gallery is built like a classical garden of Suzhou. There is a teahouse in the gallery, where you can listen to the qin (a local musical instrument) and drink tea. You can experience Suzhou embroidery courses. There are experienced local embroideresses to guide you. Even novices don't have to worry about not being able to embroider' (T1).

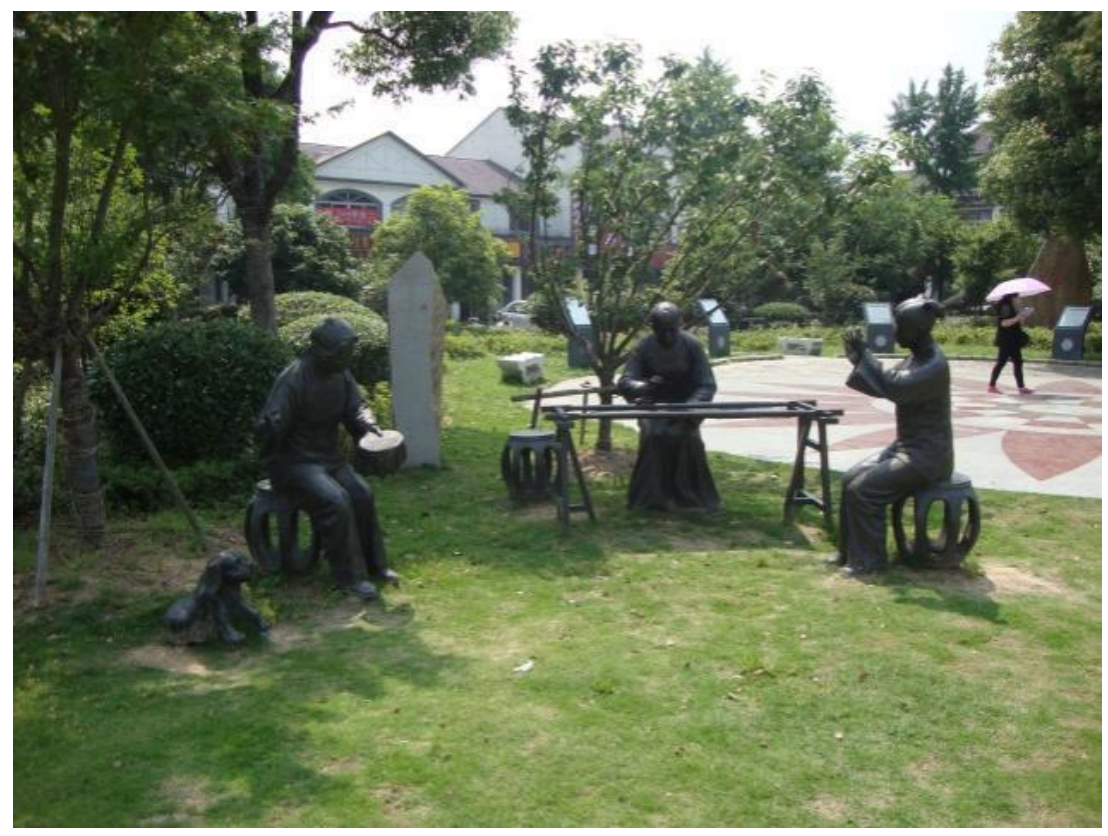

Figure 6. Suzhou-embroidery-themed sculpture landscape on a street corner.

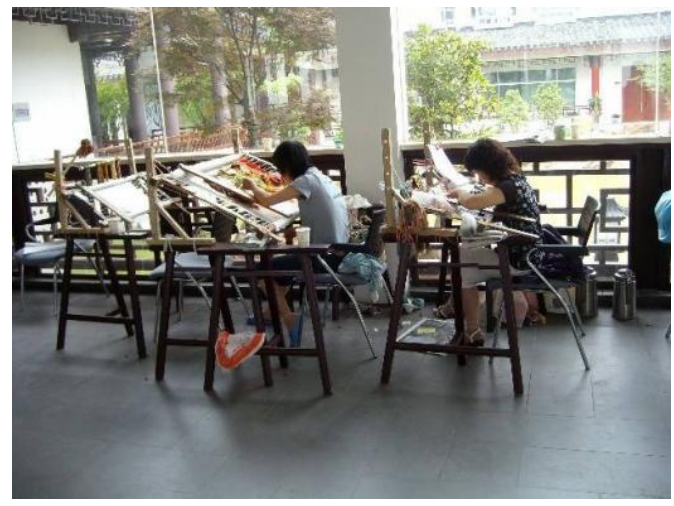

(a)

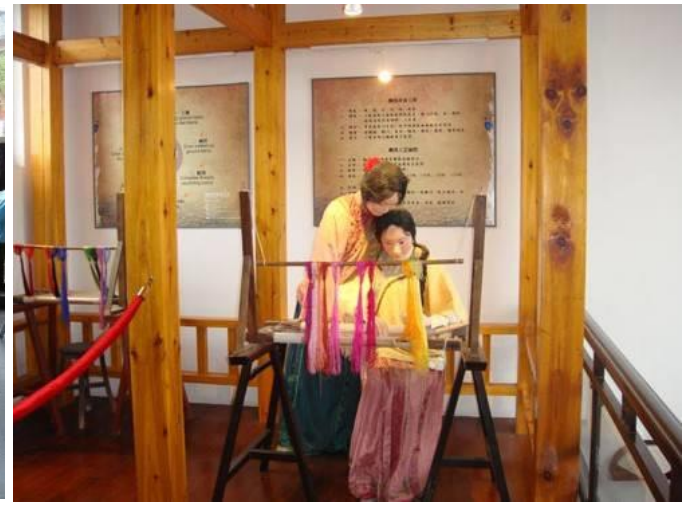

(b)

Figure 7. (a) The Dynamic display of embroidery scenes in the Chinese Embroidery Art Gallery (b) The static showcase of embroidery scenes in the Chinese Embroidery Art Gallery.

Thus, the form of public spaces in Zhenhu has changed significantly, and the architectural landscape has changed from the traditional rural to a classical Jiangnan style architecture to appeal to the public geographical imagination. A rich and accessible Suzhou embroidery cultural landscape has thus developed in the place. The China Embroidery Art Museum was built in Zhenhu to attract the visitors who are interested in the Suzhou em- 
broidery culture, creating favorable conditions for tourism development. At the same time, the booming of the Suzhou embroidery culture greatly depends on the development of tourism, which poses both opportunities and challenges for local sustainable development.

What is worth exploring is that this kind of implanted local landscape reconstruction currently only covers the core area of Zhenhu's well-developed region, leaving the surrounding area in its most original features, as observed by the researchers during the field survey. There is a distinct dividing line between the landscapes of both areas, and they are not perfectly coordinated. Therefore, although local residents accept landscape implantation, foreign landscapes undermine the holism of the local landscapes, fragmenting the continuity among local landscapes.

\subsection{Programming of Activities in the Place}

\subsubsection{Development of Production Activities}

Embroidery Street provides exhibition and sales spaces for the embroidery industry, and this change of physical space has led to the development of embroidery production activities.

The main change is the emergence of 'store-in-front-and-workshop-behind' style of embroidery studios. This new approach has replaced the original home-based workshop and has led to an increase in production and marketing efficiency. The new style of embroidery studio consists of a store in front for exhibiting and selling embroidery products and a workshop at the back (Figure 8). Before Embroidery Street was built, the most common approach was the home-based workshop mode of production and sales. The embroideresses made and sold embroidery products at home or at private workshops: 'In the past, you could see an embroidery stand in front of every house in the village. Most embroideresses worked in the courtyards of their homes during the day and night' (E2); 'In the past, we had no place to do business, and we didn't have a good marketing strategy. Buyers came to visit us at home [to see goods and negotiate prices] attracted by our products. It was not convenient' (ESO2). Embroidery studios not only produce and sell embroidery products but also provide technical training to embroideresses and have thus become multi-functional embroidery spaces.

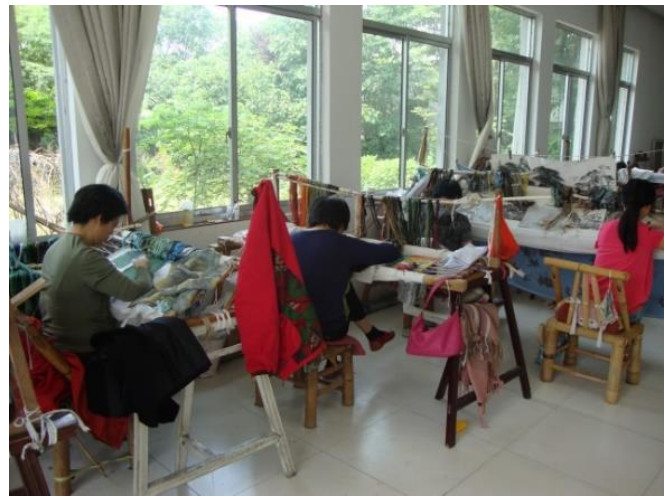

(a)

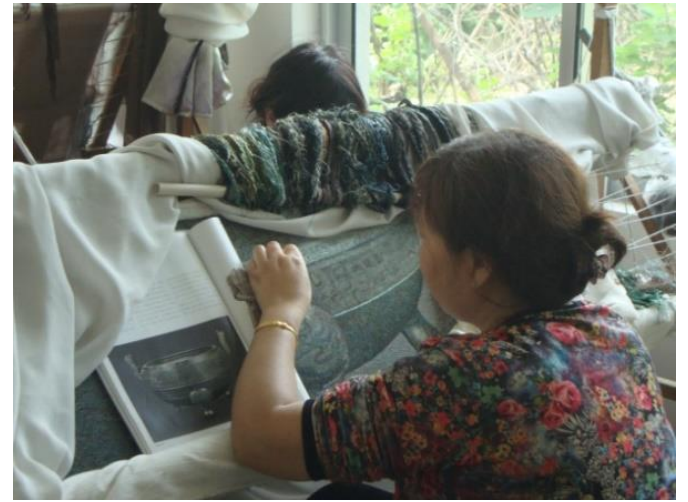

(b)

Figure 8. (a) Production activities in an embroidery studio; (b) An Embroideress embroiders carefully.

Innovation and creativity in the industry have also improved. Embroideresses in Zhenhu no longer simply create products but are now involved in product design and brand creation. This signals the beginning of the transformation of the industry: 'In the past, we all did odd jobs. Now I have my own embroidery studio, and I can choose and design my own patterns' (ESO4). Innovations in subjects, patterns, and styles have emerged in the studios, bringing Suzhou embroidery more in line with modern aesthetics. Products can be customised, and embroidery skills are constantly updated. Zhenhu embroideresses have invented various new stitching methods and have obtained patents. Over 20 kinds of Suzhou embroidery stitches are currently used: 'Historically, Suzhou embroidery have made great artistic achievements, but there are excellent embroiderers in every era. In recent years, the 
techniques and themes of Zhenhu's Suzhou embroidery have been evolving, and we are all learning and innovating' (SCR3).

The transmission of embroidery skills has also evolved from being solely through the family to a combination of channels, and the inheritance of skills has become more stable. Zhenhu girls generally learn embroidery through the family tradition of mothers teaching daughters and women teaching their husbands' younger sisters [87]. This family tradition is unstable, as the learnt skills are limited by those of their mothers: 'I picked up the needle at the age of six and learned to embroider flowers from my mother. This is how girls of our generation started embroidering' (SCR2); 'Under my mother's wings, it is difficult for me to make a breakthrough' (SCR3); 'Every family in Zhenhu used to have four or five children, now it has only one [due to China's one-child policy]. If she doesn't learn embroidery, her mother's craft won't pass on' (SCR1). The Zhenhu Embroidery Association has held embroidery workshops and competitions since the revival of the industry, and larger embroidery studios conduct training and provide multiple channels for learning embroidery skills [88]. Thus, various channels for the transmission of embroidery skills now coexist in Zhenhu: 'The association organises more than a dozen or twenty embroidery workshops every year. If young people want to learn embroidery, we can match them up by finding teachers and platforms' (GO3).

The local production practice has therefore changed. The home-based workshop approach mode of production was first transformed into the 'store-in-front-and-workshopbehind' studio-based style. Innovation and creativity in the industry have also improved. The transmission of embroidery skills has evolved from solely through the family to multiple channels, and the inheritance of skills has become more stable. All of these changes have resulted from the shift in handicraft production from a household sideline to a more industrialised approach. In addition, the development of Suzhou embroidery culture provides references on dynamic inheritance and sustainable development of intangible cultural heritage.

\subsubsection{Transformation of the Local Lifestyle}

The revival of handicrafts has had a profound impact on the daily life of residents, which is mainly reflected in changes to their livelihoods and social interactions.

First, their lifestyles have been modernised as a result of the changes to their livelihoods. Farmers in Zhenhu used to earn their livings mainly through crop farming, along with fishing and embroidery. As the embroidery industry has developed and expanded, it has become the main occupation and source of income. Increasingly, more Zhenhu residents are engaged in embroidery-related activities, such as sales, mounting, transportation, and the supply of fabrics and silk threads: 'I used to do business in other towns. When the embroidery business in my hometown refreshed, I came back to do sales and tend the store. Now most of my family's income comes from embroidery' (ESO5). The change of livelihood has led to lifestyle changes. The lives of Zhenhu residents were based around traditional agriculture and they worked from sunrise to sunset and were only engaged in embroidery in their spare time. Now embroidery has become a full-time occupation, and embroideresses commute to and from work: 'When I was a child, embroideresses embroidered in their spare time. Now, in more than 400 embroidery studios, embroideresses are almost whole-heartedly dedicated to the career' (SCR1); 'Although we live in the countryside, we live the life of office workers in the city. We come to work at 7 a.m. and leave at 4:30 p.m. every day' (E6). Many embroideresses have moved from the countryside to the towns: 'My hometown is in Mashan Village. Our land has been transferred to the cooperative. My whole family live in Xiu'an Garden Community in the town. My child goes to a primary school in the town, my husband works as a security guard in the town, and the parents help run the embroidery business' (ESO2).

Second, the revival has stimulated local social interaction and has helped to open up the formerly closed agricultural society of Zhenhu. Frequent cultural exchanges between local people now occur, and residents' social networks have expanded. The increase in embroidery-related cultural events in Zhenhu, including exhibitions, forums, competitions, and festivals, has promoted the spread and communication of Zhenhu's Suzhou 
embroidery culture. Suzhou has held the Chinese Embroidery Culture and Art Festival every April since 2008, with Zhenhu as the main venue, and has become an important local cultural event [89]: 'We are committed to ensuring the success of the Chinese Embroidery Culture and Art Festival and making it truly a national embroidery culture and tourism event. The embroidery culture and art festival is very helpful for promoting the Suzhou embroidery brand of Zhenhu' (GO3). Tourists now visit Zhenhu and the Chinese Embroidery Art Gallery as part of their road trips and buy Suzhou embroidery products, and residents provide services such as catering, accommodation, and embroidery demonstrations and classes, thus enabling them to establish contacts with people from outside of the local area. Thus, the social networks of local people have greatly expanded.

In summary, the traditional farming lifestyle of Zhenhu residents has been modernised and urbanised by the revival and development of handicrafts. The handicraft industry brings about an easier life and improves living conditions, which helps prevent population outflow, solve the issue of family separation, and eliminate hidden community threats. This is conducive to community stability.

\subsection{Constructing the Meaning of Places}

The meaning of a place represents a cultural dimension that acquires ever-changing cultural connotations in the process of constant interaction between the place and the external world and people [90]. It suggests the unique character of the place and how it is understood. The study found significant changes in the perceptions of place, in terms of Zhenhu's image and identity.

\subsubsection{Changes in the Perceptions of the Place Image}

The public perception of Zhenhu has changed dramatically. Zhenhu was relatively underdeveloped economically before the revival of Suzhou embroidery, lacking any representative sites, relics, or iconic symbols: 'In the past, people knew little about Zhenhu. There was nothing special, and it was very poor' (R1); 'Before there were many embroidery businesses along the Taihu Lake, and embroidery was not unique to Zhenhu' (GO1). After the expansion of the market, Zhenhu gained broad cultural influence and popularity, and Suzhou embroidery now represents Zhenhu's unique label: 'With the popularity of Suzhou embroidery growing, more and more people have come to know Zhenhu and know that embroidery is produced here' (R4); 'Now when people talk about Suzhou embroidery, they will mention Zhenhu, and vice versa' (T2). Thus, Zhenhu has shaped its image as a 'Suzhou embroidery town'. In addition to the construction of its architectural and cultural landscapes, Zhenhu also projects a beautifully tranquil image consistent with the characteristics of classical women in ancient China, which shapes public imagination about the place and the perceptions of it. Figure 9 shows scenes of a promotional video being shot in the embroidery art gallery, with embroideresses dressed in traditional cheongsams working in a lakeside pavilion. Zhenhu is then associated with colourful silk threads, beautiful embroideresses, tranquil scenes, and natural scenery, which encourages a romantic and positive public perception of the place. In various promotional videos, as well as film and television works, embroidery-related scenes are managed artistically in this way. However, this also brings the effect of unrealistic and over-edited aesthetics to the construction of local image. In fact, embroideresses do not perform their craft outdoors; also, embroidery is more laborious rather than romantic. These are all done for the sake of marketing and "packaging" the location.

In summary, the public perception of Zhenhu has changed profoundly from an initial lack of knowledge to the current distinct image of a 'Suzhou embroidery town', and it now has a place image characterised by the quiet and beautiful temperament of the Chinese women of ancient times, although there are concerns about over-glamorization and inauthenticity. 


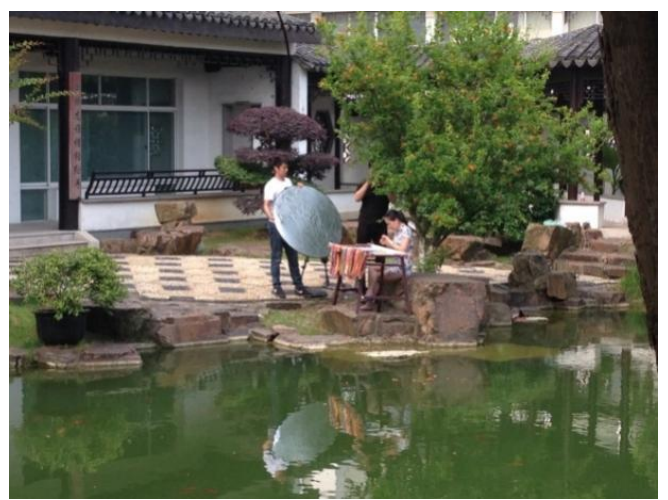

(a)

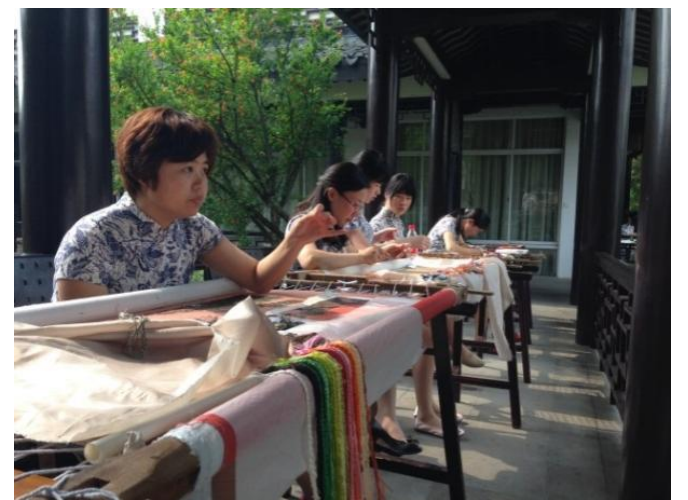

(b)

Figure 9. (a) Scenes of a promotional film being shot; (b) embroideresses dressed in traditional cheongsams for shooting the film.

\subsubsection{Enhancing Residents' Sense of Place}

The place has become more important for residents. The development of the embroidery industry has improved the available resources and provided more employment opportunities and higher incomes, which has strengthened the residents' economic dependence on the place. In 2018, about $40 \%$ of Zhenhu's population was engaged in embroidery-related work. The increased personal development opportunities and resource level reinforces residents' functional connections with the place: 'Zhenhu's Suzhou embroidery is growing in popularity and attracts buyers and distributors from all over the country. The embroidery sales platform here is the best' (ESO1). The local income level has increased significantly, and embroidery has become the main source of income for many rural households in Zhenhu, exceeding that from farming: 'At present, $75 \%$ of the income of farmers in Zhenhu comes from embroidery' (GO4). Residents' intentions toward the place may have also changed: 'I was a migrant worker. When the embroidery business started to revival in my hometown, I came back to tend the store' (ESO3). The beautification of public spaces and the improvement of facilities have also increased residents' functional dependence on the place: 'It's much more beautiful than before, and life is easier. There used to be dirt roads in our town. Now there are wide paved roads and bus services' (R2). Improved and modernised public facilities bring convenience to residents, which enhances their quality of life.

They have a more positive perception of cultural heritage, which in turn increases their sense of place. The inclusion of Suzhou embroidery on the national intangible cultural heritage list is a recognition of its cultural value. The identification of local residents with Suzhou embroidery and the place have improved accordingly: 'In the past, people did not think highly of embroidery. When children were not obedient, adults would tell them, "If you don't study hard, you will have to do embroidery work in the future." This is akin to sweeping the streets in other places. They thought that people who had no skills would do this' (SCR1); 'I never expected Suzhou embroidery to have such a high value. Previously, embroidery was a very common and low-level job here, but now I feel a little proud' (E1). As a form of cultural heritage, Suzhou embroidery has gained greater public recognition and attention, and thus the affection residents feel for the place deepens: 'At the mention of Suzhou embroidery Zhenhu comes to the mind. We are full of pride' (R1).

The transformation of the landscape and the changes to local life did not reduce the sense of place previously held by some residents. Some thought that no substantial changes had occurred: 'We have been living our life (doing embroidery) all along. I do not feel anything different, except that the environment is better' (E3). Some residents were aware of the changes, understood them, and even looked forward to further change: 'I feel nostalgic (for the old place), but the place has to develop and change' (R1); 'You cannot find a place that's not changing. It is for the better, progress' (R6). 
To sum up, the revival of handicraft is conducive to community stability. This is consistent with the local sustainable development goals. As the residents have better understanding about cultural heritages, they would gain a stronger sense of belonging and identity, and achieve closer contact, both financially and emotionally, with the community. This helps prevent population outflow and keep the residents better bounded with the community.

\section{Discussion}

The above analysis reveals that the revival of traditional handicrafts can bring major changes to a place in terms of its physical spaces, activities, and meaning. The construction of placeness and the mechanism in this process are summarized in Figure 10.

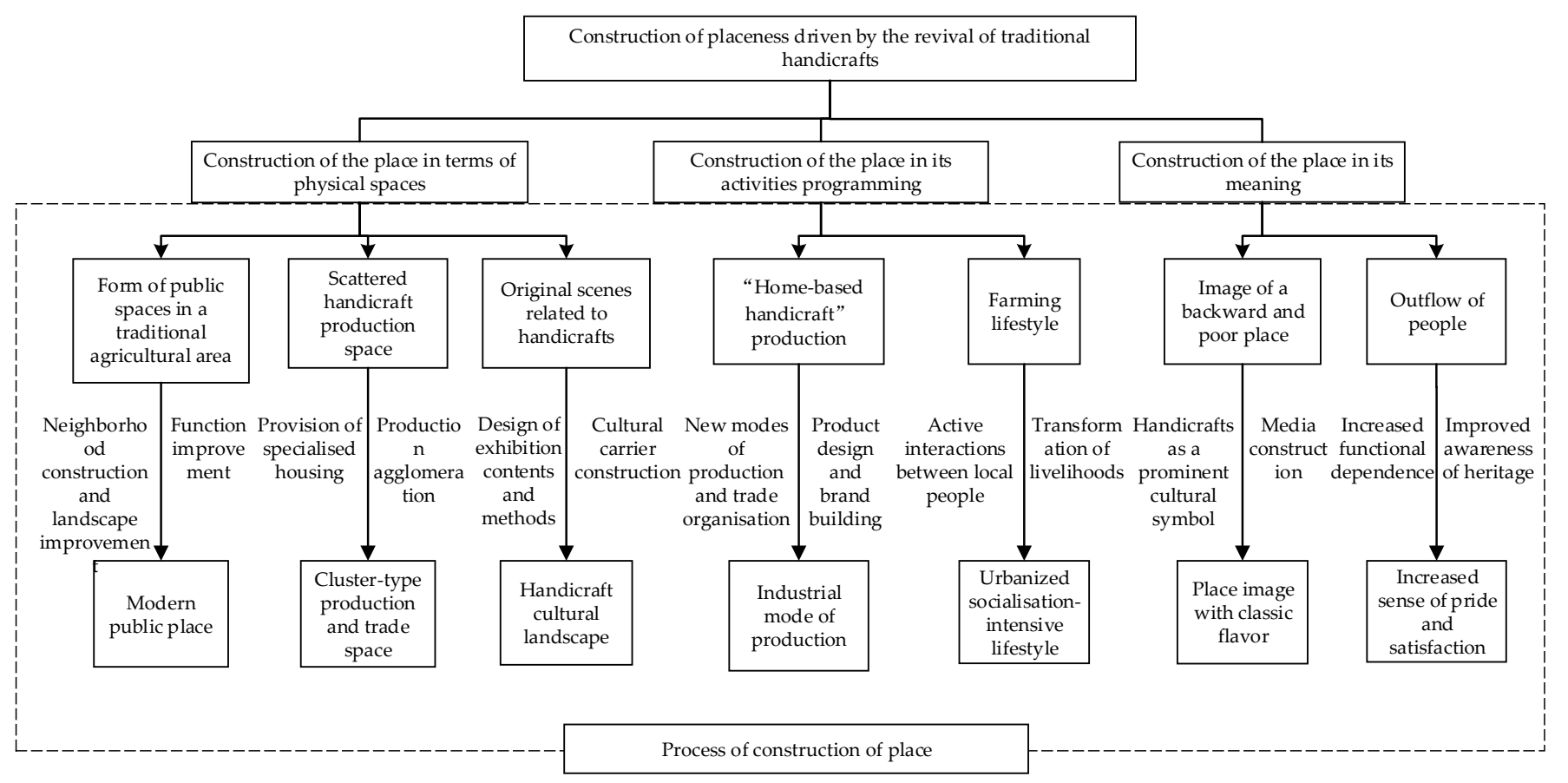

Figure 10. Construction of place driven by the revival of handicrafts.

In this context, the process of reformulating the place's physical spaces involves modernising public spaces, reconfiguring the architectural landscape, and creating a handicraftbased cultural landscape. This process not only enhances the existing placeness but also encourages the transformation toward a new placeness. Through the rapid construction of modern neighbourhoods and landscaping, the local government reconstructed the form and function of the place, which led to changes in the place's activities and its image. Commercial blocks and large-scale architectural edifices replaced farmland and residential buildings, low-rise residential buildings transformed into an exquisite Jiangnan-style classical architectural landscape, and this landscape became a symbol of the place and a medium through which its image was delivered. Thus, the landscape is transformed and its placeness has changed. Other studies have shown that the transformation of local landscape morphology and the spatial function of a place, combined with common spatial practices, can disconnect the place from local history and social traditions and change its cultural meaning, leading to a gradual shift toward placelessness [34,91]. However, in Zhenhu, the evolution of the local landscape did not lead to the dissolution of placeness, and the transformation of the architectural style is in line with the public geographical imagination of Suzhou embroidery and has given rise to new landscape features. The ubiquitous presence of handicrafts in the place is its own expression of placeness, and the resulting handicraft cultural landscape is a natural extension of placeness. The construction of spaces is influenced by the development of traditional handicrafts and involves the 
inheritance of, respect for, and the expression of the local history and culture, and the new local landscapes are therefore integrated with its history and culture. At the same time, however, it should also be admitted that this embedded local landscape reconstruction is not perfectly coordinated with the original features, and that there is a distinct dividing line between the landscape of the well-developed area and that of the rural area, which entails a winding process of coordination and integration with the original features.

Studies have shown that urban construction and economic and industrial development can be a driving force for the dissolution of placeness, as they can lead to a featureless physical environment, a weak sense of place among residents, and can even bring about the dissolution of placeness [39]. Placeness has been endowed with new characteristics and meanings through the development of local industries [10]. The case study of Zhenhu shows that reviving traditional handicrafts can lead to the development of production in a place and modernised lifestyles. The effects of this economic and industrial development can be generalised to other areas, but in Zhenhu, the specific effects have been to update the organisation and production of the handicraft industry, enhance innovation and creativity within it, and stabilise the inheritance of handicraft skills. However, the development of these traditional handicrafts is based on the fact that the majority of residents have knowledge of the skills through inheritance, which are thus embedded in common perceptions and local memories. The construction of place, as driven by handicrafts, therefore extends history and strengthens the traditional culture and local characteristics, rather than depriving residents of their sense of place and disconnecting them from history. Some residents did not perceive that any major changes had occurred to the place, as they had been working in the handicraft trade all along. For the residents of Zhenhu, the revival of traditional handicrafts has brought about the beautification of physical spaces and the improvement of facilities. It has also provided better resources, employment opportunities, and higher incomes, enabling them to improve their quality of life and broaden their social networks. The residents' perceptions of the intangible cultural heritage that they are personally involved in have also improved, and traditional handicrafts are regarded as a precious form of heritage. This has strengthened the residents' local identities, sense of belonging, and feelings of pride in the place. Surely, the residents also keep some nostalgic recollections of their past lives, but that's more of a reminiscent sentiment; the fact is, residents show a considerate attitude towards changes in the location.

This study also reveals that traditional handicrafts can play an important role in creating a place's image and shaping the public's geographical imagination. The public perception of Zhenhu has undergone profound changes, from an initial lack of knowledge to the present clear perception of a 'Suzhou embroidery town', and the association of the place's image with the quiet and beautiful temperament of Chinese women from ancient times. This indicates that the features of the place are more distinct than before, and that its meaning has been strengthened and enhanced. However, we must also be able to notice the presence of over-polished and unrealistic aesthetics in the process that are aimed at "packaging" and marketing the location, trading-off the most authentic parts of the location and heritage.

As discussed above, industrial development in Zhenhu is strictly restricted in order to protect the Taihu Lake. Polluters such as chemical plants and paper mills are shut down and relocated. Local GDP ranks at the bottom among all towns in Suzhou. To strike the balance between economic development and ecological protection, what do the locals do to get rid of poverty? How can sustainable development be achieved in the areas where industrial development is strictly restricted? Zhenhu is a good case to study this topic. It taps into the potential of traditional handicraft, the revival of which contributes to local sustainable development in the following way (Figure 11). 


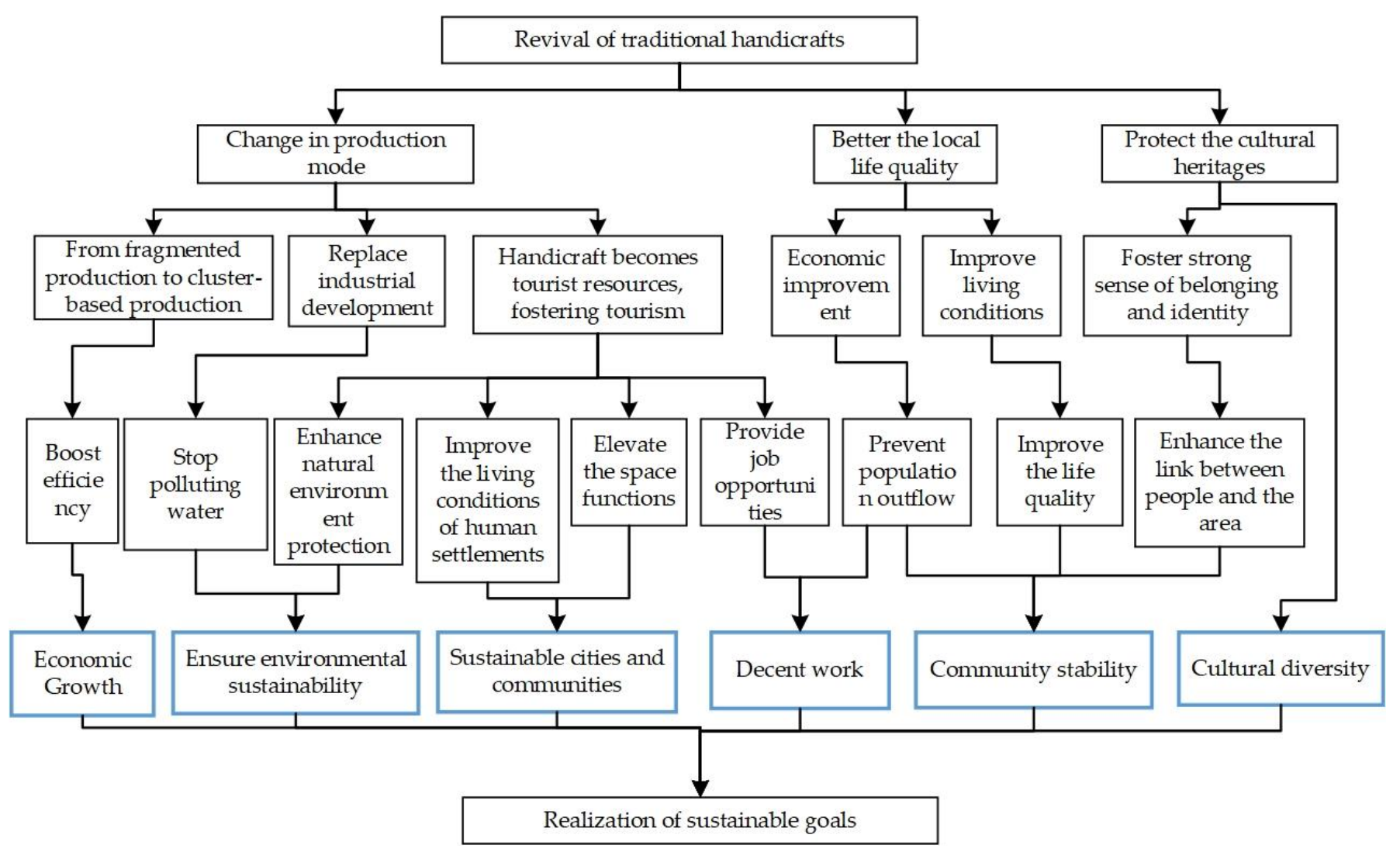

Figure 11. Intangible cultural heritage facilitates the realization of the sustainable development goals.

The revival of handicraft is conducive to sustainable economic growth. Along with the upgrade of the production mode, the embroidery industry in Zhenhu grows from fragmented production to cluster-based production. The family workshops change into the store-workshop pattern, upgrading the production-sales chain, boosting industrial efficiency, and meeting the economic growth needs. By shutting down the polluters, Zhenhu gets rid of the industries that pollute the environment and elevates the local economic growth. In the absence of industrial economy, the embroidery industry in Zhenhu witnesses a revenue increase from RMB 270 million in 2002 to RMB 1.29 billion in 2012 [92,93], growing into the local pillar industry.

The local environment gains better sustainability. Zhenhu protects the Taihu Lake by shutting down all chemical plants, improving the black and odorous water bodies, and building the sewage discharge network [94]. Zhenhu ensures safe drinking water, no massive lake flooding, and no massive blue-green algae in the downtown rivers and lakes [95]. The development of tourism places higher requirements on the quality of the natural environment. No open-air barbecuing is allowed along the dikes of Taihu Lake [96]. Zhenhu manages to create more jobs without causing land and resource scarcity or damaging the environment.

Sustainable communities are built. The revival of traditional handicraft improves the local operation mechanism, enriches the functions of public space, and solves issues such as inconvenient traffic, lacking sewage treatment facilities and infrastructures, and poor living conditions. All these efforts make Zhenhu a convenient, comfortable and safe living area. The development of tourism contributes to improving the human settlements, including local landscapes. These changes are essential to build a sustainable community.

Reviving handicraft creates more jobs. The rise of the handicraft industry creates jobs and business opportunities related to embroidery. The booming tourism industry also provides jobs. Those who once left Zhenhu returned to their hometown to work or start 
businesses. The handicraft industry boosts economic growth without undermining the local environment.

The revival of handicraft is conducive to community stability, which is consistent with the local sustainable development goals. The handicraft industry brings about a growing economy and improves living conditions, which helps prevent population outflow, solve the issue of family separation, and eliminates hidden community threats. As the residents have better understanding about cultural heritages, they would gain a stronger sense of belonging and identity and achieve closer contact with the community. All these contribute to building harmonious and stable community.

At the same time, cultural heritage protection boosts cultural diversity, which is particularly crucial to sustainable development. As stated by the Universal Declaration on Cultural Diversity, cultural diversity is the source of exchanges, innovation and creation, and "the key of sustainable human development." A common challenge in the sector of intangible cultural heritage protection lies in the lack of inheritors and instable inheritance channels [97]. In the revival of handicraft in Zhenhu, increased industrial benefits bring about more incomes to local families, attracting more people to learn these skills. At the same time, there are changes in the skill inheritance. More channels emerge, ensuring stable skill inheritance. The growing embroidery industry overcomes the challenge of insufficient inheritors and provides valuable lessons on cultural heritage.

According to case study, the revival of traditional handicraft contributes to local sustainable development in the following ways. On one hand, the traditional handicraft industry has little impact on the environment and relies on the wisdom, creativity, and manual work of the craftsmen. It will not endanger the environment or cause resource scarcity, meeting the environmental requirements of sustainable development. On the other hand, traditional handicraft is both cultural heritage and local industry. The protection and inheritance of cultural heritage is closely related to the development of local industries. As a local cultural symbol, cultural heritage helps protect cultural diversity and enhances the ties between the locals and the community, while local industries bring about a booming economy. In other words, the development of traditional handicraft involves the social and economic aspects of sustainable development. It not only fosters natural development but facilitates the realization of the sustainable development goals.

Based on the local practices in Huzhen, the tourist development of traditional handicraft helps achieve part of the sustainable goals. However, the tourist development of intangible cultural heritage should be treated with remarkable prudence because negative impacts have emerged in other cases. For instance, the excessive commercialization of intangible cultural heritages results in the mutations of the culture in the tourist destinations, which is adverse to sustainable development. Zhenhu is at the early stage of tourist development. The development does bring such benefits as natural environment protection, improved living conditions, more jobs, and closer social contacts. These are in line with the sustainable development goals. The purchase of the traditional handicraft products will not undermine the nature of cultural heritage. No cultural shock or subject-object conflicts happen at this stage. More attention should be paid to the possible negative impact on sustainable development when the tourism industry matures.

It is worth noting that traditional handicraft is not necessarily a perfect mode to following the sustainable development path. Issues remain with the sustainable development of Zhenhu: two-thirds of local revenues come from handicraft, and two thirds of local residents work in the embroidery industry. With a single source of income, Zhenhu is not flexible enough to deal with an industrial crisis. This is against the requirements of sustainable development. More pillar industries should be fostered to increase the income sources.

This study has some limitations. The public spaces, landscapes, and activities in the place before the revival of handicrafts were traced and pieced together based on local records and residents' memories. Primary material was not available, nor were any authoritative images. 
The construction of the forms of physical spaces in the place, the activities in the place, and the meaning endowed to it by the intangible cultural heritage of traditional handicrafts were the focus of this study. The development of different types of intangible heritage will lead to different effects and changes to the place. For example, traditional performing arts, folk festivals, and sports may have very different modernising effects on their host heritage sites. The process and characteristics of each will be unique in their effect on constructing placeness. Thus, how specific types of intangible cultural heritage construct placeness is worthy of attention. In addition, interpreting placeness systematically in a broader social context would be of benefit.

\section{Conclusions}

In conclusion, traditional handicrafts are rooted in the place, and their revival can guide the place to return to a greater dependency on the local economy and to engage in cultural construction. This will ensure the natural continuation of local heritage and culture and the strengthening and development of placeness. The revival of handicrafts and the development of the place leads to changes in physical spaces, including the enhancement of public spaces and characteristic landscapes. The activities of the place will also change, including the transformation of production and the modernisation of lifestyles. Such changes are expected and required by local residents, as they provide a sense of security and belonging and help to develop a sustainable and healthy environment. The formation of the place image brought about by the revival of traditional handicrafts and the raising of residents' awareness of their cultural heritage will improve the quality of placeness and can lead to extensive developments in the meanings and features of the place. The revival of traditional handicrafts is thus an important means of resisting globalisation and homogenisation and maintaining and enhancing placeness.

These local changes exert positive impact on the realization of sustainable goals by boosting decent work and economic growth, ensuring environmental sustainability, building sustainable cities and communities, and enhancing community stability and cultural diversity.

Author Contributions: X.Z. and Y.L. jointly conceived, designed and wrote the paper; X.Z., Y.L. and J.L. jointly analysed the data; Y.Y. made the maps; and J.L. improved the quality of the manuscript. All authors have read and agreed to the published version of the manuscript.

Funding: This research was funded by Beijing Social Science Fund (20GLC061).

Institutional Review Board Statement: Not applicable.

Informed Consent Statement: Not applicable.

Conflicts of Interest: The authors declare no conflict of interests.

\section{References}

1. Tuan, Y.-F. Topophilia: A Study of Environmental Perception, Attitudes and Values; Prentice- Hall Inc.: Hoboken, NJ, USA, $1974 ;$ p. 3.

2. Relph, E. Place and Placelessness; Routledge Kegan \& Paul: London, UK, 1976; pp. 4-9.

3. Tuan, Y.-F. Space and Place: The Perspective of Experience; Minnesota University Press: Minneapolis, MI, USA, 1977.

4. McGuigan, J. Culture Methodologies; Li, C.-Y., Ed.; Peking University Press: Beijing, China, 2011.

5. Zhu, H.; Qian, J.; Feng, L. Negotiating place and identity after change of administrative division. Soc. Cult. Geogr. 2011, 12, 143-158. [CrossRef]

6. Oakes, T. Place and the paradox of modernity. Ann. Assoc. Am. Geogr. 1997, 87, 509-531. [CrossRef]

7. Ritzer, G. The Globalization of Nothing; Wang, Y.-Q., Ed.; Shanghai Yiwen Publication: Shanghai, China, 2004.

8. Ethical Principles for Safeguarding Intangible Cultural Heritage. Available online: https://ich.unesco.org/en/Decisions/10 .COM/15.a (accessed on 21 July 2021).

9. He, K.-D. Revival of the Traditional Handicrafts of Jingdezhen in the New Economic Situation. China Ceram. 2015, 51, 88-91.

10. Yang, J.; Xu, C.; Zhu, H. Placeness reconstruction under the influence of local industry: A cultural economic geographical study of the jadeware industry in Yangmei Village. Sci. Geogr. Sin. 2020, 40, 374-382.

11. Song, G.-Y. The Cultural Characteristics of Suzhou Embroidery. Lit. Cont. 2010, 4, 142-144.

12. Xiao, M.-L. Exploration of customs in The State of Wu and Yue. Southeast Cult. 1988, Z1, 83-88. 
13. Wan, J.-H. The State of Wu and the State of Yue in the Spring and Autumn Period and its Culture. Tian Jin Shi Fan Da Xue Xue Bao She Ke Ban 1988, 3, 55-59.

14. Digital Museum of Chinese Intangible Cultural Heritage. Available online: http://www.ihchina.cn/project_details/13978/ (accessed on 20 July 2021).

15. Lu, X.-Y.; Xu, S.-Q. Development comparison of Suzhou embroidery in three western Suzhou towns, the place of origin of Suzhou embroidery. Silk Tec. 2018, 35-41.

16. Gregory, D.; Johnston, R.; Pratt, G.; Watts, J. The Dictionary of Human Geography, 5th ed.; Wiley-Blackwell: West Sussex, UK, 2009; p. 539.

17. Crang, M. Cultural Geography; Yang, S.-H., Song, H.-M., Eds.; Nanjing University Press: Nanjing, China, 2003 ; pp. 127-152.

18. Eyles, J. The Geography of Everyday Life; Macmillan: London, UK, 1989; pp. 102-117.

19. Cooke, P. Localities: The Changing Face of Urban Britain; Unwin Hyman: London, UK, 1989.

20. Harvey, D. The Condition of Postmodernity: An Enquiry into the Origins of Cultural Change; Blackwell: Oxford, UK, 1989.

21. Smith, N. The New Urban Frontier; Rout ledge: New York, NY, USA, 1996.

22. Pred, A.; Watts, M. Reworking Modernity; Rutgers University Press: New Brunswick, NJ, USA, 1992.

23. Kearney, A.; Bradley, J.-J. Too strong to ever not be there: Place names and emotional geographies. Soc. Cult. Geogr. 2009, 10, 77-94. [CrossRef]

24. Gao, Q.; Qian, J. Negotiating place-restructuring from the perspective of emotional geographies: A case study of Liede village, Guangzhou. Hum. Geogr. 2016, 31, 33-41.

25. Rose, G. The cultural politics of place: Local representation and oppositional discourse in two films. Transact. Inst. Brit. Geog. 1994, 19, 46-60. [CrossRef]

26. Gregory, D. The production of regions in England's Industrial Revolution. J. Hist. Geogr. 1988, 14, 50-58. [CrossRef]

27. Massey, D. A global sense of place. Marxi. Tod. 1991, 24-29.

28. Harvey, D. Justice, Nature and the Geography of Difference; Basil Blackwell: Oxford, UK, 1989.

29. Chen, X.-L. The accumulation and consumption of place: The emergence of "Lizhiwan" and the blanking of "Enning Road". Tour. Trib. 2013, 28, 11-12.

30. Jiang, L.; Su, Q. The Impact of Tourism to Placeness in Ancient Town: Multiple Cases in Zhouzhuang. Sci. Geogr. Sinic. 2016, 36, 766-771.

31. Dai, J.-C.; Zhou, S.-Y. On mechanism of place making in the view of "historical layers" theory: A case of Donggaocun Town in Beijing. Hum. Geogr. 2015, 30, 16-21.

32. Greenwood, D.J. Culture by the Pound: An Anthropological Perspective on Tourism as Cultural Commoditization, Hosts and Guests: The Anthropology of Tourism; Smith, V., Ed.; University of Pennsylvania Press: Philadelphia, PE, USA, 1989; pp. 171-185.

33. Cohen, E. Authenticity and Commoditization in Tourism. Ann. Tour. Res. 1988, 15, 371-386. [CrossRef]

34. Short, J.R. Imagined Country: Society, Culture and Environment; Routledge: London, UK, 1991; p. 221.

35. Shim, C.; Santos, C.A. Tourism place and placelessness in the phenomenological experience of shopping malls in Seoul. Tour. Manag. 2014, 45, 106-114. [CrossRef]

36. Lin, M.-H.; Bao, J.-G. Tourism Commodification in China's Historic Towns and Villages: Re-examining the Creative Destruction Model. Tour. Trib. 2015, 30, 12-22.

37. Salcedo, R. When the global meets the local at the mall. Am. Behav. Sci. 2003, 46, 1084-1103. [CrossRef]

38. Wu, F. The (post-)socialist entrepreneurial city as a state project: Shanghai's reglobalisation in question. Urban stud. 2003, 40, 1673-1698. [CrossRef]

39. Kong, X.; Chen, D. The influence of suburban development zones on deconstruction of placeness of the host regions: A case of Changsha economic and technological development zone. Hum. Geogr. 2016, 31, 26-32.

40. Zheng, S.-L.; Xue, X.-M.; Zhu, H. Newborn tourist place: The place reconstruction in "post-disaster recovery" contextualized Bailu village, Pengzhou City, Sichuan Province. Tour. Trib. 2017, 32, 59-70.

41. United Nations World Commission on Environment and Development. Our Common Future; Wang, Z.-J., Ke, J.-L., Eds.; Jilin People's Press: Changchun, China, 1997; pp. 52-143.

42. Schrijver, N. The Evolution of Sustainable Development in International Law: Inception, meaning and status; Wang, X.-G., Huang, H.-B., Eds.; Social Sciences Academic Press: Beijing, China, 2010; p. 194.

43. Song, Y. Chinese Yearbook of International Law; Law Press: Beijing, China, 2019; p. 369.

44. Convention for the Safeguarding of the Intangible Cultural Heritage 2003. Available online: http:/ / portal.unesco.org/en/ev.phpURL_ID=17716\&URL_DO=DO_TOPIC\&URL_SECTION=201.html (accessed on 18 July 2021).

45. Millennium Development Goals and Beyond 2015. Available online: https://www.un.org/millenniumgoals / (accessed on 18 July 2021).

46. Intergovernmental Conference on Cultural Policies for Development: Final Report. Available online: https://unesdoc.unesco. org/ark: / 48223/pf0000113935?posInSet=1\&queryId=e31721c2-f6f8-47ab-8482-29b99a38129e (accessed on 18 July 2021).

47. Records of the General Conference, 31st Session, Paris, 15 October to 3 November 2001, v. 1: Resolutions (chi). Available online: https:/ / unesdoc.unesco.org/ark:/48223/pf0000124687_chi.page=81 (accessed on 18 July 2021).

48. Zhang, T.; Wen, H.; Li, X. A Tourist-Based Model of Authenticity of Heritage Sporting Events: The Case of Naadam. Sustainability 2019, 108. [CrossRef] 
49. Caust, J.; Vecco, M. Is UNESCO World Heritage recognition a blessing or burden? Evidence from developing Asian countries. J. Cult. Herit. 2017, 27, 1-9. [CrossRef]

50. Dernini, S.; Berry, E.M.; Serra-Majem, L.; La Vecchia, C.; Capone, R.; Medina, F.X.; Aranceta-Bartrina, J.; Belahsen, R.; Burlingame, B.; Calabrese, G.; et al. Med Diet 4.0: The Mediterranean diet with four sustainable benefits. Public Health Nutr. 2017, 20, 1322-1330. [CrossRef]

51. Chung, H.; Lee, J. Community Cultural Resources as Sustainable Development Enablers: A Case Study on Bukjeong Village in Korea compared with Naoshima Island in Japan. Sustainability 2019, 11, 1404. [CrossRef]

52. Bentor, Y. Tibetan Tourist Thangkas in the Kathmandu Valley. Ann. Tour. Res. 1993, 20, 107-137. [CrossRef]

53. Ryan, C.; Crotts, J. Carving and Tourism: A Maori Perspective. Ann. Tour. Res. 1997, 24, 898-918. [CrossRef]

54. Ryan, C. Tourism and Cultural Proximity: Examples from New Zealand. Ann. Tour. Res. 2002, 29, 952-997. [CrossRef]

55. Simpson, B. Tourism and Tradition from Healing to Heritage. Ann. Tour. Res. 1993, 20, 164-181. [CrossRef]

56. Daniel, Y.P. Tourism Dance Performances: Authenticity and Creativity. Ann. Tour. Res. 1996, 23, 780-797. [CrossRef]

57. Chronis, A. Constructing Heritage at the Gettysburg Story scape. Ann. Tour. Res. 2005, 32, 386-406. [CrossRef]

58. Park, H.Y. Shared National Memory as Intangible Heritage: Re-imagining Two Koreas as One Nation. Ann. Tour. Res. 2011, 38 , 520-539. [CrossRef]

59. Zhenhu Sub-district Chorography Compiling Committee. Local Records of Zhenhu Sub-District; Publishing House of Local Records: Beijing, China, 2019.

60. China Green Times. Completely New Moves: Higher-Level Comprehensive Governance of Water Pollution to Lake Taihu. Available online: http:/ / www.greentimes.com/greentimepaper/html/1999-01/05/content_201038.htm. (accessed on 19 July 2021).

61. Stunning Suzhou Embroidery \& Featured Intangible Cultural Heritage-The Best to Learn from the Suzhou Embroidery Towns of Jiangsu Province. Available online: https: / / kns.cnki.net/KXReader/Detail?TIMESTAMP=637646549716619923\&DBCODE= CJFD\&TABLEName=CJFDLAST2019\&FileName=ZJMD201909014\&RESULT=1\&SIGN=B8UhltWfYy5Zb\%2b4GnlxP8vtfX6Y\% 3d\# (accessed on 15 August 2021).

62. Zhenhu Town Chorography Compiling Committee. Local Records of Zhenhu Town; Publishing House of Local Records: Beijing, China, 2015.

63. Notifications of the State Council to Disclose the List for the First State-Level Non-Material Cultural Heritages. Available online: http:/ / www.gov.cn/zhengce/content/2008-03/28/content_5917.htm (accessed on 19 July 2021).

64. Decisions of the Ministry of Culture to Name the Second National Cultural Industry Demonstration Bases. Available online: http:/ / zwgk.mct.gov.cn/zfxxgkml/cyfz/202012/t20201206_916898.html (accessed on 19 July 2021).

65. Su, F. Craftsmen who have survived-Investigation reports from Suzhou hi-tech zone. Shanghai Econ. 2004, 16-17.

66. Brocki, J.; Wearden, A. A critical evaluation of the use of interpretative phenomenological analysis in health psychology. Psychol. Health 2006, 21, 87-108. [CrossRef]

67. Denzin, N.; Lincoln, Y. Strategies of Qualitative Inquiry; Sage: London, UK, 2008; pp. 1-43.

68. Ayres, L.; Kavanaugh, K.; Knafl, K. Within-case and across-case approaches to qualitative data analysis. Qual. Health Res. 2003, 13, 871-883. [CrossRef]

69. Flick, U. Triangulation in qualitative research. Companion Qual. Res. 2004, 3, 178-183.

70. Hong, H. The embroidered lady who goes to the world. China Soc. Period. 2004, 10, 48-49.

71. Wang, X. On Boudoir Embroidery in Su Embroidery Art. J. Zhejiang Fashion Inst. Technol. 2014, 13, 76-79.

72. Lin, X.-D. Additional information about Suzhou embroidery industry. Arch. Constr. 2000, 57-58.

73. Duan, B.-L.; Zhang, Q.-F. The History of Suzhou Handicraft Industry; Jiangsu Ancient Books Publishing House: Nanjing, China, 1986.

74. Suzhou Evening News. Stories behind Suzhou Embroidery Patterns. Available online: https://www.sohu.com/a/197580262_73 6451 (accessed on 19 July 2021).

75. Dongzhu Town Chorography Compiling Committee. Records of Dongzhu Town; Shanghai Dictionary Publishing House: Shanghai, China, 2007.

76. Tong'an Town Chorography Compiling Committee. Records of Tong'an Town; Shanghai Dictionary Publishing House: Shanghai, China, 2007.

77. Suzhou News. Tong'an Spent RMB 45 Million to Build Tens of Thousands Mu of Plantation Landscape. Available online: http:/ /news.cntgol.com/jdgz/2017/0720/147475.shtml (accessed on 20 July 2021).

78. Tens of Thousands Mu of Modern Agricultural Garden to Pave a New Way for Economic Prosperity via Integrative Development of Three Industries. Available online: http:/ / www.snd.gov.cn/hqqrmzf/jnctdcbjy/201707/1f9f14fd1ab546e0b71291f497805cbd. shtml (accessed on 20 July 2021).

79. Xu, M.-Y. Reflections and trial to enhance traditional cultural industry development-new development orientation for Zhenhu embroidery industry. Orient. Enterp. Cult. 2011, 14, 229.

80. Stitch Techniques Popular for Suzhou Embroidery. Available online: https: $/ / \mathrm{kns} . \mathrm{cnki}$. net $/ \mathrm{kcms} / \mathrm{detail} / \mathrm{detail}$.aspx?dbcode= CJFD\&dbname=CJFDLAST2016\&filename=DAJS201609033\&v=iaWUgoSoT28xMjjFAMd65DNUDjiwLP8slvw\%25mmd2FvA3 cHBohfDDf\%25mmd2FPzgiT80JnLPdEKU (accessed on 15 August 2021).

81. He, F. Technical integration and artistic innovation-Yao Jianping embroidery exhibition opened at National Art Museum of China. Art Obs. 2016, 2, 37. 
82. Embroidery Art Museum of China Officiqally Unveiled. Available online: http://www.gov.cn/govweb/fwxx/wy/2007-09/28 / content_763929.htm (accessed on 21 July 2021).

83. China's First 4A Embroidery Culture Scenic Spot to Be Established in The Hi-Tech Zone. Available online: http://news.eastday. $\mathrm{com} / \mathrm{csj} /$ 2013-09-02/667764.html (accessed on 21 July 2021).

84. Zhen, X.; Cang, W. Embroidery Art Museum of China to qualify for national 4A tourist spot. Real. Only 2013, 4, 19-20.

85. Dong, X. On the Images of Chinese Cities South of the Yangtze River in American Media. J. Tongji Univ. 2019, 30, 103-114.

86. Li, J.-Y. A brief analysis of the relations between Suzhou embroidery and folk culture of the Wu areas. Art Sci. Tec. 2016, 29, 153.

87. Liu, J. Cultural inheritance of the featured Suzhou embroidery towns-The charm of school-based curriculum. People's Educ. 2019, 21, 68-69.

88. Yang, C.-Y.; Zhang, J.-Y.; Wei, H.-T. Exploration on the Long-term Vocational Technical Education System According to the Development of Expertise-Taking the Example of Suzhou Embroidery Talent Cultivation. Adult Educ. 2015, 35, 58-62.

89. China Embroidery Culture \& Art Festival Opened. Available online: http://www.huaxia.com/zhwh/whxx/2019/04/6084753. html (accessed on 21 July 2021).

90. Massey, D. Power-geometry and a progressive sense of place. Mapp. Futur. Local Cult. 1994, 933, 491-496.

91. Sun, J.-X.; Huang, X.-B.; Wang, X.-J. The de-localization tendency of tourism streets: Based on the perspective of institutional disembeddment. Tour. Trib. 2017, 32, 24-33.

92. Digital Museum of Chinese Intangible Cultural Heritage. Zhenhu, A Town Well-Known for Suzhou Embroidery-Striking A Good Balance Between Traditional and Modern Elements. Available online: http:/ / www.ihchina.cn/Article/Index/detail?id=10500 (accessed on 22 July 2021).

93. A Yearly Income of RMB 1.3 Billion in Zhenhu Earned from Embroidery Industry. Available online: http://sz.wenming.cn/ whsz/201311/t20131118_900367.shtml (accessed on 22 July 2021).

94. The official website of Suzhou Huqiu District Government. The List for Polluted Waters in Urban and Township Areas of Suzhou Hi-Tech District to Be Treated in 2018. Available online: http://www.snd.gov.cn/hqqrmzf/ggl/201805/67afcb770d3a4ebf92bb2 6a40956a387.shtml (accessed on 22 July 2021).

95. Well-Prepared for the Fight against Pollution 15 Key Projects of the Year Put on the Agenda. Available online: https://www. szdushi.com.cn/news/201803/151987654458254 (accessed on 22 July 2021).

96. Say No to Open-Air Barbecue Business at Lake Taihu Dam Scenic Spot Special Rectification Campaign Launched by Zhenhu Urban Management Office. Available online: http:/ /news.2500sz.com/doc/2019/04/01/421780.shtml (accessed on 21 July 2021).

97. Hao, W.-J. A probe into the features of inheritors of intangible cultural heritage and their inheriting effects. J. Commer. Econ. 2013, 7, 145-146. 